\title{
The Application of the Multivariate GARCH Models on the BRICS Exchange Rates
}

\author{
Dr. Lebotsa Daniel Metsileng \\ Prof. Ntebogang Dinah Moroke \\ Dr. Johannes Tshepiso Tsoku \\ North West University, \\ Mmabatho, South Africa
}

DOI: https://doi.org/10.36941/ajis-2020-0058

\begin{abstract}
The study investigated the BRICS exchange rate volatility using the Multivariate GARCH models. The study used the monthly time series data for the period January 2008 to January 2018. The BEKK-GARCH model revealed that all the variables were found to be statistically significant. The diagonal parameters estimates showed that only Russia and South Africa were statistically significant. This implied that the conditional variance of Russia and South Africa's exchange rates are affected by their own past conditional volatility and other BRICS exchange rates past conditional volatility. The BEKK-GARCH model also revealed that there is a bidirectional volatility transmission between Russia and South Africa. The results from the DCC-GARCH model revealed that Brazil, China, Russia and South Africa had the highest volatility persistence and India has the least volatility persistence. All the BRICS exchange rates show that the fitted residuals are not normally distributed except for Russia. The recommendations for future studies were articulated.
\end{abstract}

Keywords: Multivariate GARCH, BRICS Exchange rates, Volatility, BEKK-GARCH model, DCC-GARCH model

\section{Introduction}

In this study, the focus was to provide an account of recent theoretical advances in Multivariate GARCH models and their applications in macroeconomic and financial time series. Minović and Simeunović (2009) gave literature review on the Multivariate GARCH model in the modern finance and economy. Furthermore, it is being documented that Multivariate GARCH model has a variety of applications. The leverage effects of the Multivariate GARCH model are also discussed in the study. The Multivariate GARCH models take into account the volatility clustering and heteroskedastic property of the variance and covariance which are some of the features of financial time series. The study hopes to identify appropriate Multivariate GARCH models for the BRICS exchange rates.

The rest of the study is organized as follows: the literature review is presented in Section 2. Section 3 provides the methodology applied in the study. The results and discussions of the results are presented in Section 4. The conclusion of the study is presented in Section 5. 


\section{Literature Review}

Bala and Takimoto (2017) used the Multivariate GARCH model and its variants in investigating stock returns volatility spill-overs in emerging and developed markets. Furthermore, Bala and Takimoto (2017) analysed the 2007 to 2009 global financial crisis on the interactions of the stock market and the BEKK-GARCH-type models was modified by including financial crisis dummies to determine their impact on volatility and spill-overs. The results showed an improved diagnostics with the DCC-withskewed-t density model as compared to other models because financial returns often present fat tails and skewed features.

The study by Ijumba (2013) on the Multivariate GARCH models suggested that there was a persistence of volatility amongst the BRICS stock market returns and this was also found in the study by Türkyılmaz and Balıbey (2014). Chen and Zapata (2015) employed BEKK-GARCH models in order to model volatility and spill-over effects and the results revealed that own-price volatility and past unexpected events explain the volatility in China price hogs and America's volatility is explained by its own events. The study by Türkyılmaz and Balıbey (2014) generated the conditional variances of monthly stock exchange prices, exchange rate and interest rates for Turkey using BEKK-GARCH model for the sample period of 2002:M1 to 2009:M1, prior to the effects of global financial crisis hit Turkey. According to the empirical results there is volatility among these three financial sectors and an indication of significant transmission of shocks.

Minović (2017) reviewed both the theoretical and empirical for diagnostic checking of Multivariate volatility processes. The study by Minović (2017) used the Ljung-Box statistics (Q-stat) of standardized residuals, those of its squared, as well as of the cross product of standardized residuals to test the adequacy of the model. The results show for model adequacy the residual-based diagnostics provide a useful check. Furthermore, based on the overall results models performed statistically well.

Sheu and Cheng (2011) employed both the VAR and the Multivariate GARCH model for two sets of periods 1996 to 2005 and 2006 to 2009 in comparing the effects of volatility for the China and Unites States (US) stock market respectively on the Taiwan and Hong Kong. It is found that China's stock market is independent and co-moments with other markets are still insignificant.

Bonga-Bonga and Nleya (2016) compared the performance of the constant conditional correlation (CCC), dynamic conditional correlation (DCC) and asymmetric DCC (ADCC) models in estimating the portfolio at risk in the BRICS countries. The study employed the average deviations, quadratic probability function score and the root mean square error as the performance error measurement. The results showed that portfolio is the way to minimise the losses in BRICS.

The volatility and conditional relationship among inflation rate, exchange rate and interest rates together with constructing a model of Multivariate GARCH DCC and BEKK were investigated by Nortey et al. (2015) using a dataset of Ghana covering the period of January 1990 to December 2013. The study found that the BEKK model is robust in modeling and forecasting volatility of inflation rate, exchange rate and interest rate whereas the DCC model is robust in modeling the conditional and unconditional correlation of the inflation, exchange and interest rates respectively.

Gardebroek et al. (2013) employed Multivariate GARCH approach in assessing the interdependence and dynamics of volatility in corn, wheat and soybeans markets in the U.S on a daily, weekly and monthly basis covering 1998 to 2012. Based on the results there was an indication of lack of cross boarder dependence between markets and on weekly basis there exists volatility between these commodities.

Hartman and Sedlak (2013) used a ten years exchange rate data and examined the performance of the two Multivariate GARCH models: BEKK and DCC. The performance is measured based on the OLS regression, MAE and RMSE. Based on the results it is found that the BEKK model performance better than the DCC model. The study by Tastan (2006) employed the Multivariate GARCH model in assessing the interaction between exchange rate and stock market returns. The series used was a daily data of Euro-Dollar exchange rate and the Dow Jones Industrial average and $\mathrm{S} \mathrm{P}_{500}$ index from the 
US economy. The study found that the conditional volatility of the each variable is determined by their own shock.

Efimova and Serletis (2014) compared both the univariate and Multivariate GARCH models in terms of investigating the empirical properties of oil, natural gases and electricity price volatility. The data set used is the daily data of whole sale markets in the US covering the period of 2001 to 2013 . The models were compared using the range of performance tests together with assessing the conditional correlation dynamics. Chen and Zapata (2015) employed BEKK-GARCH model in order to model volatility and spill-over effects using the data covering the sample of June 1996 to December 2013. According to the results it is documented that own-price volatility and past unexpected events explains the volatility in China's price hogs, whereas American volatility is explained by its own events.

The study by Chen and Zapata (2015) examined both the short run and long run linkages between equity markets in China and the US in terms of exploring and comparing the effects of two financial crises (Asian 1997 Financial Crisis and the Subprime 2007 to 2010 Financial Crisis). Furthermore, the BEKK-GARCH model is estimated in order to examine the volatility spill-over effects. According to the results there exists not the cointegration in the stock indexes of the mainland to that of both the US and Hong Kong. However, there exists volatility and spill-over effects in the short run in the different equity markets.

Yi et al. (2009) augmented fractionally integrated VECM model with the Multivariate GARCH model to reveal simultaneously the return transmission and volatility spill-over between market return series. The empirical results showed that there is a fractional integration and China's market is strongly tied with Hong Kong market than with the U.S market. Baybogan (2013) estimated the volatility in financial time series econometrics and also investigated the empirical application with respect to estimation applications in the theoretical framework of GARCH models. The two models investigated are both the DCC-GARCH and BEKK-GARCH. Kvasnakova (2009) employed both the copula and Multivariate GARCH model in modeling the returns of the growth pension funds. The study again applied the two models in calculating the VaR and compares them. The results show that copula model produces better VaR estimation.

\section{Methodology}

The study used the monthly BRICS exchange rate data for the period January 2008 to January 2018. The study used the monthly exchange rates of the five BRICS countries. The data used the US Dollar as the standard currency for all the five BRICS countries. The data was obtained from the Organisation for Economic Cooperation and Development (OECD) website. The analysis was carried out using R 3.4.4 programming language. The following subsections discusses the models used to model the BRICS exchange rates.

\subsection{Multivariate Garch Model}

The Multivariate GARCH model is basically the extension of the univariate GARCH models that it is significant to predict the dependence in the co-movement of the BRICS countries. According to Kroner and Ng (1998), there are several Multivariate GARCH model formulations which have been proposed in the literature. The most popular Multivariate GARCH models are the diagonal BEKK, the diagonal VECH, CCC and DCC models. For a Multivariate time series $\mathrm{Y}_{\mathrm{t}=} \mathrm{y}_{1 \mathrm{t}}, \mathrm{y}_{2 \mathrm{t}}, \mathrm{y}_{3 \mathrm{t}}, \ldots, \mathrm{y}_{\mathrm{kn}}$ the Multivariate GARCH model is given by

$$
\mathrm{y}_{\mathrm{t}}=\mathrm{P}_{\mathrm{t}}^{1 / 2} \varepsilon_{\mathrm{t}}
$$

where $\mathrm{P}$ denotes a $\mathrm{k} \times \mathrm{k}$ positive definite matrix and of the conditional variance of $\mathrm{C}_{\mathrm{t}}, \mathrm{k}$ represent the number of series and $t=1,2, \ldots, n$ where $n$ is the number of observations (Nortey et al., 2015). It is with the specification of conditional variance that the Multivariate GARCH model changes. 
Bollerslev (1986) describes a general GARCH (p. q) as follows

$$
\begin{aligned}
& \mathrm{h}_{\mathrm{t}}=\alpha_{0}+\alpha_{1} \varepsilon_{\mathrm{t}-1}^{2}+\cdots+\alpha_{\mathrm{p}} \varepsilon_{\mathrm{t}-\mathrm{p}}^{2}+\beta_{1} \mathrm{~h}_{\mathrm{t}-1}+\cdots+\beta_{\mathrm{q}} \mathrm{h}_{\mathrm{t}-\mathrm{q}} \\
& \alpha_{1}>0, \beta_{1}>0, \alpha_{1}+\beta_{1}<1
\end{aligned}
$$

where $h_{t}$ is conditional variance dependent on the previous error term as well as the previous conditional variance of the process. The main issue in Multivariate GARCH is to develop the conditional variance-covariance matrix (S) from equation (2). It is transferred into Multivariate GARCH model with a generalization of the resulting variance matrix $S_{t}$ below

$$
\mathrm{S}_{\mathrm{t}}=\left(\begin{array}{lll}
\mathrm{h}_{11} & \mathrm{~h}_{12} & \mathrm{~h}_{13} \\
\mathrm{~h}_{21} & \mathrm{~h}_{22} & \mathrm{~h}_{23} \\
\mathrm{~h}_{31} & \mathrm{~h}_{32} & \mathrm{~h}_{33}
\end{array}\right)
$$

Every element of $S_{t}$ is dependent on the p delayed values of the squared $\varepsilon_{t}$, the cross product of $\varepsilon_{t}$ and on the $q$ delayed values of elements from $S_{t}$.

\subsubsection{The diagonal VECH}

The diagonal VECH is the first general model introduced by Bollerslev et al. in 1988. According to Bunnag (2015:107), "in the VECH model, every conditional variance and covariance is a function of all lagged conditional variances and covariances, as well as lagged squared returns and cross-products of returns". The model can be expressed below

$$
\operatorname{VECH}\left(H_{t}\right)=c+\sum_{j=1}^{q} D_{j} \operatorname{VECH}\left(\varepsilon_{t-j} \varepsilon_{t-j}^{\prime}\right)+\sum_{j-1}^{p} E_{j} \operatorname{VECH}\left(H_{t-j}\right)
$$

where, VECH $\left(H_{t}\right)$ is a column stacking operator of the lower triangular part of its argument square matrix, $H_{t}$ is the covariance matrix of the residuals, $\mathrm{N}$ denotes the number of variables, $t$ is the index of the $t^{t h}$ observation, $c$ is a $\left.\frac{1}{2}(N(N+1) \times 1)\right)$ vector, $D_{j}$ and $E_{j}$ are $\frac{1}{2}(N(N+1)) \times$ $\frac{1}{2}(N(N+1))$ parameter matrices and $\varepsilon$ is an $N \times 1$ vector (Bunnag, 2015).

Baba et al. (1990) introduced the new parameterization of the conditional variance matrix $H_{t}$ was developed to ensure the non-negative definiteness. The model was later known as BEKK model. The BEKK model is the restricted version of the VECH model.

\subsubsection{The diagonal BEKK}

The BEKK model was introduced by Engle and Kroner (1995). The model is the direct generalization of the univariate GARCH model. The outcome variance depends on the state of the information present. The form of the BEKK model is as

$$
H_{t}=C C^{\prime}+\sum_{j=1}^{q} \sum_{j=1}^{k} D^{\prime}{ }_{k j} \varepsilon_{t-j} \varepsilon_{t-j}^{\prime} D_{k j}+\sum_{j=1}^{q} \sum_{j=1}^{k} E^{\prime}{ }_{k j} H_{t-j} E_{k j}
$$

where $D_{k j}, E_{k j}$ and $C$ are $N \times N$ parameter matrices and $C$ is a lower triangular matrix that enforce the positive definiteness of $H_{t}$. In a BEKK model application, it is assumed that $\mathrm{p}=\mathrm{q}=\mathrm{k}=1$ to ensure a positive definiteness of $H_{t}$. The first order BEKK model is given as

$$
H_{t}=C C^{\prime}+D^{\prime} \varepsilon_{t-1} \varepsilon^{\prime}{ }_{t-1} D+E^{\prime} H_{t-1} E
$$

The BEKK model also has its diagonal form by assuming $D_{k j}, E_{k j}$ matrices are diagonal. This model is a restricted version of the diagonal VECH model.

\subsubsection{The CCC models}

Bollerslev in 1990 introduced the CCC model to fundamentally model the conditional covariance matrix. The conditional covariance matrix was modelled by estimating the conditional correlation matrix. The CCC model by Bollerslev (1990) is presented as

$$
\begin{array}{ll}
y_{t}=F\left\langle y_{t} \mid G_{t-1}\right\rangle+\varepsilon_{t}, & \varepsilon_{t}=D \eta_{t} \\
\operatorname{Var}\left\langle\varepsilon_{t} \mid G_{t-1}\right\rangle=D_{t} \Gamma D_{t} & \\
\text { where, } y_{t}=\left(y_{1 t}, \ldots \ldots y_{m t}\right)^{\prime} & \eta_{t}=\eta_{1 t}
\end{array}
$$


distributed (i.i.d ) random vector. $\mathrm{G}_{\mathrm{t}}$ is the past information available at time t. $D_{t}=\operatorname{Diag}\left(h_{t}^{\frac{1}{2}}, \ldots h_{m}^{\frac{1}{2}}\right)$. The conditional variance for each exchange rates $h_{i t}, \mathrm{i}=1 \ldots \ldots . ., \mathrm{m}$ are similar to univariate GARCH process, which follows

$$
\sigma_{t}^{2}=\lambda_{0}+\sum_{i=1}^{q} \lambda_{1} \varepsilon_{t-1}^{2}+\sum_{i=1}^{p} \alpha_{i} \sigma_{i-1}^{2}
$$

where $\lambda_{0}, \lambda_{1}$ and $\alpha_{i}$, are nonnegative and $\sum_{i=1}^{q} \lambda_{i}+\sum_{i=1}^{p} \alpha_{i}$ for $\mathrm{i}=1 \ldots \mathrm{k}$.

\subsubsection{The DCC models}

The CCC model was deemed to be inconsistent with reality in accordance with (Longin and Solnik, 1995, 2001). Therefore, Engle (2002) developed a new Multivariate dynamic conditional correlation GARCH model to address the inconsistencies raised in relation with the CCC model. Due to the dynamic nature of the model, it was termed DCC-GARCH model, and it has the dynamic presumption of conditional correlation coefficients among different variables. Engle (2002) introduced the DCC model and was illustrated below

$$
H_{t}=D_{t} R_{t} D_{t}
$$

where $R_{t}$ is the conditional correlation matrix of the exchange rates vector $r_{t}=r_{1 t}, \ldots \ldots r_{n t}$, $D_{t}=\operatorname{diag}\{\sqrt{\text { hit }}\}$ is a $5^{*} 5$ diagonal matrix and $R_{t}$ matrix is given by

$$
\begin{aligned}
& R_{t}=\operatorname{diag}\left(Q_{t}\right)^{-1} Q_{t} \operatorname{diag}\left(Q_{t}\right)^{-1} \\
& Q_{t}=\left(1-v_{1}-v_{2}\right) \bar{Q}+v_{1}\left(\eta_{t-1} \eta_{t-1}^{\prime}\right)+v_{2} Q_{t-1}
\end{aligned}
$$

where $Q_{t}=\left\{\rho_{i j}\right\}$ is a (time-invariant) $\mathrm{K}^{\star} \mathrm{K}$ positive definite parameter matrix with unit diagonal elements. The DCC-GARCH model is process is estimated by the MLE method and the log-likelihood is expressed as follows

$$
L=\frac{-1}{2} \sum_{t=1}^{T}\left(n \log (2 \pi)+2 \log \left|D_{t}\right|+\log \left|R_{t}\right|+\varepsilon_{t}^{\prime} R_{t}^{\prime} \varepsilon_{t}\right)
$$

From the above four models, diagonal VECH, the diagonal BEKK, CCC and DCC models, the paper will focus on the BEKK model and the DCC. An advantage of the BEKK model is that $\mathrm{E}^{\prime}$ is positive definite if the diagonal elements of $C$ is positive and $D C C$ has a $K^{\star} K$ positive definite parameter matrix with unit diagonal elements. The main reason is to make sure that there is the condition of a positive-definite conditional-variance matrix in the process of optimization. The other advantage is that the number of parameters will reduce/decrease, but the positive definiteness will not be lost in the process.

\subsubsection{Model Estimation for Multivariate GARCH}

Following the conditional normality assumption, the parameters of BEKK-GARCH models can be estimated using the maximisation of the log likelihood function

$$
\mathrm{L}(\mathrm{v})=-\frac{\mathrm{TN}}{2} \log 2 \pi-\frac{1}{2} \sum_{\mathrm{t}=1}^{\mathrm{T}}\left\langle\log |\mathrm{H}|+\varepsilon_{1}^{\prime} \mathrm{H}_{\mathrm{t}}^{-1} \varepsilon_{\mathrm{t}}\right\rangle
$$

where $v$ represents all the parameters to be estimated, $N$ denotes the number of the series in the system and $\mathrm{T}$ is the number of observations. The BHHH (Berndt, Hall, Hall and Hausman) algorithm is used to maximize the above log likelihood function.

\subsubsection{Model diagnostics}

To determine the model adequacy of the two models (BEKK-GARCH and DCC-GARCH), the following tests were employed: Ljung-Box test for serial correlation, the ARCH-LM test for constant correlation and the normality test. 


\subsubsection{Ljung-Box test}

Ljung-Box test was first introduced by Ljung and Box (1978) to test for the presence of serial correlation. The presence of serial correlation is tested using the squared standardised residual. The Ljung-Box test is computed using the following equation

$$
Q_{p}=N(N+2) \sum_{k=1}^{p} \frac{\hat{\rho}_{k}^{2}}{N-k}
$$

where $\mathrm{N}$ is the sample size and $\hat{\rho}_{k}^{2}$ represents the k-lag sample autocorrelation of the absolute or squared residuals.

\subsubsection{ARCH-LM test}

The Multivariate ARCH-LM test was introduced by Breusch (1978) and the test is meant for testing the presence of heteroskedasticity in the fitted residuals. Supposing the error vector, $u_{t}=B_{1} u_{t-1}+$ $\cdots+B_{h} u_{t-h}+\eta_{t}$, where $\eta_{t}$ is a white noise. The Multivariate ARCH-LM test is based on the following equation:

$$
\hat{u}_{t}=c+A_{1} y_{t}+\cdots+A_{p} y_{t-p}+\cdots+B_{1} \hat{u}_{t-1}+\cdots+B_{h} \hat{u}_{t-h}+\epsilon_{t}
$$

where $A_{i}$ and $B_{i}$ are coefficients matrices and $\epsilon_{t}$ is the regression error term. The following are the hypothesis tested for Multivariate ARCH-LM:

$$
\begin{aligned}
& \mathrm{H}_{\mathrm{o}}: B_{1}=B_{2}=\cdots=B_{h}=0 \text { (absence of ARCH errors) alternatively } \\
& \mathrm{H}_{1}: B_{i} \neq 0
\end{aligned}
$$

The Multivariate ARCH-LM test statistic is denoted as:

$$
L M_{h}=T \hat{c}_{h}^{\prime} \widehat{\Sigma}_{c}^{-1} \hat{c}_{h}
$$

where $c_{h}=\left(C_{1} \ldots \ldots C_{h}\right)^{\prime}$ such that $C_{h}=\frac{1}{T} \sum_{t=h+1}^{T} u_{t} u_{t-h}^{\prime}, \widehat{\Sigma}_{c}$ is the covariance matrix of the residuals.

\subsubsection{Normality test}

The goodness-of-fit test is the test used under the normality testing to determine the model fit. It compares the observed standardised residuals with the expected if the selected distribution is correct. Palm (1996) suggested a test to alter for the observation that is not i.i.d by categorising the standardised residuals by magnitude and not by value. The Adjusted Pearson goodness-of-fit statistics is computed as

$$
P(g)=\sum_{i=1}^{g} \frac{\left(n_{i}-E n_{i}\right)^{2}}{E n_{i}}
$$

where $n_{i}$ is the number of observations in cell $\mathrm{i}$ and $E n_{i}$ is the predicted number of observations using the MLE. The null hypothesis to be tested is $H_{0}$ : the data follows a given distribution (Normally distributed) and the alternative hypothesis is $H_{A}$ : the data does not follows a given distribution. If the p-value is $<0.05$ then reject the $H_{0}$.

\subsubsection{The Q-Q Plot}

The Q-Q plot is used to confirm the distribution the data follows (Mad'ar, 2014). The plot approximates the data around the straight line near the centre. If the data values deviates from the straight line, the null hypothesis of the assumed distribution for the data set is rejected.

\section{Results and Discussion}

\subsection{Multivariate Garch Using BEKK Approach}

The section presents the extension of the univariate GARCH model using a Multivariate BEKK 
approach. It provides the dynamic relations amongst the BRICS exchange rates. Table $1-3$ presents the volatility spill-overs which are mainly results from the BEKK-GARCH.

Table 1: Volatility spill-overs: Results from BEKK-GARCH model

\begin{tabular}{|c|c|c|c|c|}
\hline \multicolumn{5}{|c|}{ Triangular matrix of constant } \\
\hline Variable & Coefficient & Std. Error & t-statistic & p-value \\
\hline$B_{11}$ & 1.259 & 0.506 & 2.488 & 1.259 \\
\hline$B_{21}$ & 0.605 & 0.384 & 1.574 & 0.605 \\
\hline$B_{22}$ & 1.069 & 0.201 & $5 \cdot 308$ & 1.069 \\
\hline$B_{31}$ & 0.152 & 0.411 & 0.370 & 0.152 \\
\hline$B_{32}$ & 0.076 & 0.336 & 0.225 & 0.076 \\
\hline$B_{33}$ & 1.067 & 0.023 & 46.573 & 1.067 \\
\hline$B_{41}$ & -18.341 & 19.349 & -0.948 & -18.341 \\
\hline$B_{42}$ & -12.543 & 3.516 & -3.567 & -12.543 \\
\hline$B_{43}$ & -0.499 & 1.535 & -0.325 & -0.499 \\
\hline$B_{44}$ & 6.142 & 3.140 & 1.956 & 6.142 \\
\hline$B_{51}$ & 17.249 & 20.126 & 0.857 & 17.249 \\
\hline$B_{52}$ & 11.878 & 6.584 & 1.804 & 11.878 \\
\hline$B_{53}$ & 0.705 & 5.042 & 0.140 & 0.705 \\
\hline$B_{54}$ & $-5 \cdot 526$ & 5.806 & -0.952 & -5.526 \\
\hline$B_{55}$ & 71.665 & 5.786 & 12.385 & 71.665 \\
\hline
\end{tabular}

Table 2: Volatility spill-overs: Results from BEKK-GARCH model

\begin{tabular}{|c|c|c|c|c|}
\hline \multicolumn{5}{|c|}{ ARCH effect } \\
\hline Variable & Coefficient & Std. Error & t-statistic & p-value \\
\hline$C_{11}$ & -0.221 & 2.885 & -0.076 & 0.939 \\
\hline$C_{12}$ & -0.117 & 2.943 & -0.040 & 0.968 \\
\hline$C_{13}$ & 0.008 & 9.406 & 0.001 & 0.999 \\
\hline$C_{14}$ & 11.447 & 136.477 & 0.084 & 0.933 \\
\hline$C_{15}$ & -10.424 & $169 \cdot 354$ & -0.062 & 0.951 \\
\hline$C_{21}$ & -0.608 & 2.862 & -0.213 & 0.832 \\
\hline$C_{22}$ & -0.354 & 3.683 & -0.096 & 0.924 \\
\hline$C_{23}$ & -0.087 & 6.896 & -0.013 & 0.990 \\
\hline$C_{24}$ & 25.217 & 68.084 & 0.370 & 0.712 \\
\hline$C_{25}$ & -23.212 & 91.522 & -0.254 & 0.800 \\
\hline$C_{31}$ & -1.417 & 3.845 & -0.368 & 0.713 \\
\hline$C_{32}$ & -0.878 & 1.329 & -0.661 & 0.510 \\
\hline$C_{33}$ & -0.304 & $5 \cdot 334$ & -0.057 & 0.955 \\
\hline$C_{34}$ & 53.811 & 167.695 & 0.321 & 0.749 \\
\hline$C_{35}$ & $-49 \cdot 75^{2}$ & 66.333 & -0.750 & 0.455 \\
\hline$C_{41}$ & -1.287 & 3.147 & -0.409 & 0.683 \\
\hline$C_{42}$ & -0.803 & 1.393 & -0.577 & 0.565 \\
\hline$C_{43}$ & -0.276 & 4.492 & -0.061 & 0.951 \\
\hline$C_{44}$ & 49.276 & 134.230 & 0.367 & 0.714 \\
\hline$C_{45}$ & -45.538 & 136.807 & -0.333 & 0.740 \\
\hline$C_{51}$ & -0.768 & 3.706 & -0.207 & 0.836 \\
\hline$C_{52}$ & -0.467 & 5.440 & -0.086 & 0.932 \\
\hline$C_{53}$ & -0.135 & 10.354 & -0.013 & 0.990 \\
\hline$C_{54}$ & 30.834 & 58.633 & 0.526 & 0.600 \\
\hline$C_{55}$ & -28.417 & 72.308 & -0.393 & 0.695 \\
\hline
\end{tabular}


Table 3: Volatility spill-overs: Results from BEKK-GARCH model

\begin{tabular}{|c|c|c|c|c|}
\hline \multicolumn{5}{|c|}{ GARCH effect } \\
\hline Variable & Coefficient & Std. Error & t-statistic & p-value \\
\hline$G_{11}$ & -0.542 & 1.757 & -0.309 & 0.758 \\
\hline$G_{12}$ & -0.236 & 1.039 & -0.227 & 0.821 \\
\hline$G_{13}$ & 0.210 & 0.302 & 0.697 & 0.487 \\
\hline$G_{14}$ & 12.848 & 71.470 & 0.180 & 0.858 \\
\hline$G_{15}$ & -11.738 & 67.671 & -0.173 & 0.863 \\
\hline$G_{21}$ & -0.352 & 2.991 & -0.118 & 0.906 \\
\hline$G_{22}$ & -0.114 & 1.822 & -0.062 & 0.950 \\
\hline$G_{23}$ & 0.104 & 0.697 & 0.149 & 0.882 \\
\hline$G_{24}$ & 12.850 & 114.642 & 0.112 & 0.911 \\
\hline$G_{25}$ & -11.742 & 107.884 & -0.109 & 0.914 \\
\hline$G_{31}$ & -0.187 & 0.725 & -0.259 & 0.796 \\
\hline$G_{32}$ & -0.108 & 0.615 & -0.176 & 0.861 \\
\hline$G_{33}$ & 0.088 & 0.716 & 0.123 & 0.903 \\
\hline$G_{34}$ & 12.885 & 21.567 & 0.597 & 0.551 \\
\hline$G_{35}$ & -11.708 & 19.939 & -0.587 & 0.558 \\
\hline$G_{41}$ & -0.320 & 0.002 & -209.431 & $0.000 * * *$ \\
\hline$G_{42}$ & -0.207 & 0.002 & -97.155 & $0.000 * * *$ \\
\hline$G_{43}$ & -0.101 & 0.003 & -38.715 & $0.000 * * *$ \\
\hline$G_{44}$ & 11.771 & 0.097 & 120.884 & $0.000^{* * *}$ \\
\hline$G_{45}$ & -10.988 & 0.123 & -89.070 & $0.000 * * *$ \\
\hline$G_{51}$ & -0.321 & 0.002 & -153.158 & $0.000 * * *$ \\
\hline$G_{52}$ & -0.214 & 0.003 & -80.943 & $0.000^{* * *}$ \\
\hline$G_{53}$ & -0.121 & 0.008 & -15.947 & $0.000 * * *$ \\
\hline$G_{54}$ & 11.907 & 0.226 & 52.616 & $0.000^{* * *}$ \\
\hline$G_{55}$ & -11.126 & 0.281 & -39.664 & $0.000 * * *$ \\
\hline
\end{tabular}

The results presented in Table 1 to Table 3 depict that most of the variables are found to be statistically significant. The estimated BEKK-GARCH model can be found by substituting the following matrices into equation (5)

$$
\begin{aligned}
B & =\left(\begin{array}{ccccc}
1.259 & 0 & 0 & 0 & 0 \\
0.605 & 1.069 & 0 & 0 & 0 \\
0.152 & 0.076 & 1.067 & 0 & 0 \\
-18.341 & -12.543 & -0.499 & 6.142 & 0 \\
17.249 & 11.878 & 0.705 & -5.526 & 71.665
\end{array}\right) \\
C & =\left(\begin{array}{ccccc}
-0.221 & -0.117 & 0.008 & 11.447 & -10.424 \\
-0.608 & -0.354 & -0.087 & 25.217 & -23.212 \\
-1.417 & -0.878 & -0.304 & 53.811 & -49.752 \\
-1.287 & -0.803 & -0.276 & 49.276 & -45.538 \\
-0.768 & -0.467 & -0.135 & 30.834 & -28.417
\end{array}\right) \\
G & =\left(\begin{array}{llllll}
-0.542 & -0.236 & 0.210 & 12.848 & -11.738 \\
-0.352 & -0.114 & 0.104 & 12.850 & -11.742 \\
-0.187 & -0.108 & 0.088 & 12.885 & -11.708 \\
-0.320 & -0.207 & -0.101 & 11.771 & -10.988 \\
-0.321 & -0.214 & -0.121 & 11.907 & -11.126
\end{array}\right)
\end{aligned}
$$

Table 1 and Table 3 above presenting the estimates of the diagonal parameters show that only $\mathrm{G}_{44}$ and $\mathrm{G}_{55}$ are statistically significant at $5 \%$ level of significance. This implies that the conditional variance of Russia and South Africa's exchange rates are affected by their own past conditional volatility and other BRICS exchange rates past conditional volatility. However, $C_{11}, C_{22}, C_{33}, C_{44}, C_{55}$, 
$G_{11}, G_{22}$ and $G_{33}$ are not significant implying that the past conditional volatility does not influence volatility in the BRICS exchange rates.

The off diagonal elements of the matrix $C$ captures the cross BRICS exchange rate shock. All the off diagonal elements of the matrix $C$ are statistically insignificant, meaning that there is no spill-over effect between Brazil, India, China, Russia and South Africa's exchange rates. The negative impact each of the BRICS exchange rates have does not affect other BRICS exchange rates.

The off diagonal element of the matrix $G$ captures the BRICS exchange rate volatility transmission. Only one pair $\left(G_{45}\right.$ and $\left.G_{54}\right)$ of the off diagonal parameter is statistically significant at $5 \%$ level of significance illustrating a bidirectional volatility transmission between Russia and South Africa. The coefficients of $G_{41}, G_{42}, G_{43}, G_{51}, G_{52}, G_{53}$ and $G_{54}$ are statistically significant at $5 \%$ level of significant whereas their counterparts $\left(G_{14}, G_{24}, G_{34}, G_{15}, G_{25}, G_{35}\right.$ and $\left.G_{45}\right)$ are not statistically significant. This means that there is a unidirectional volatility transmission between Russia and Brazil; Russia and China; Russia and India, South Africa and Brazil; South Africa and China; South Africa and India; and South Africa and Russia.

The next Figure 1 illustrates the Residual Series for BEKK-GARCH model.

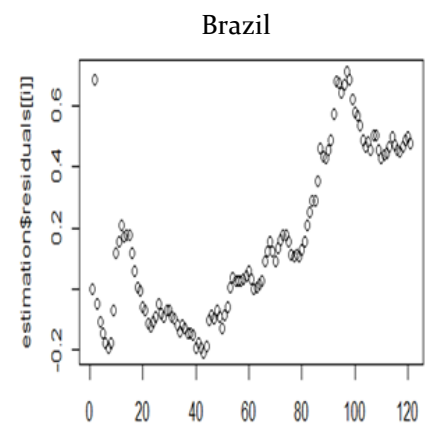

Index

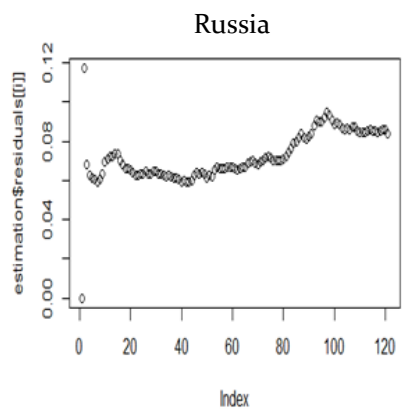

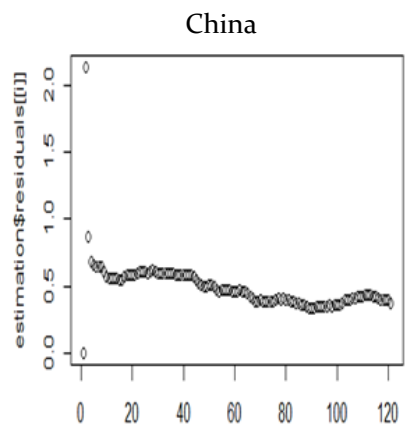

Index

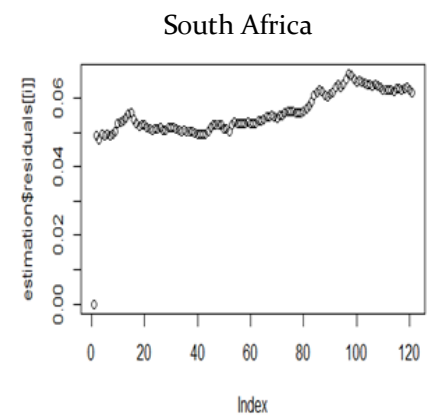

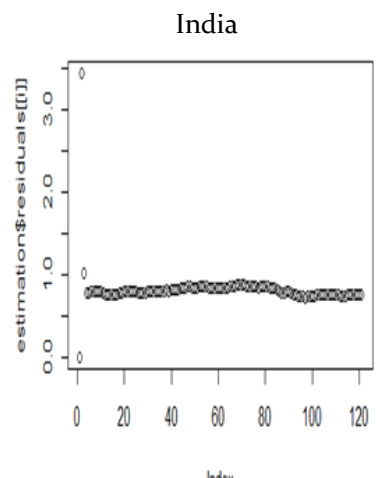

Index

Figure 1: Residual Series for BEKK-GARCH model

Figure 1 above shows that the residual series depicts a particular pattern for each of the BRICS exchange rates. Therefore, BEKK-GARCH model demonstrates the presence of autocorrelation in the residuals. Section 4.2 presents the DCC-GARCH model.

\subsection{Multivariate Garch Using DCC Approach}

The section presents the Multivariate GARCH model using a DCC approach. It provides the dynamic 
relations amongst the BRICS exchange rates. Figure 2 presents the Q-Q plots for BRICS exchange rates
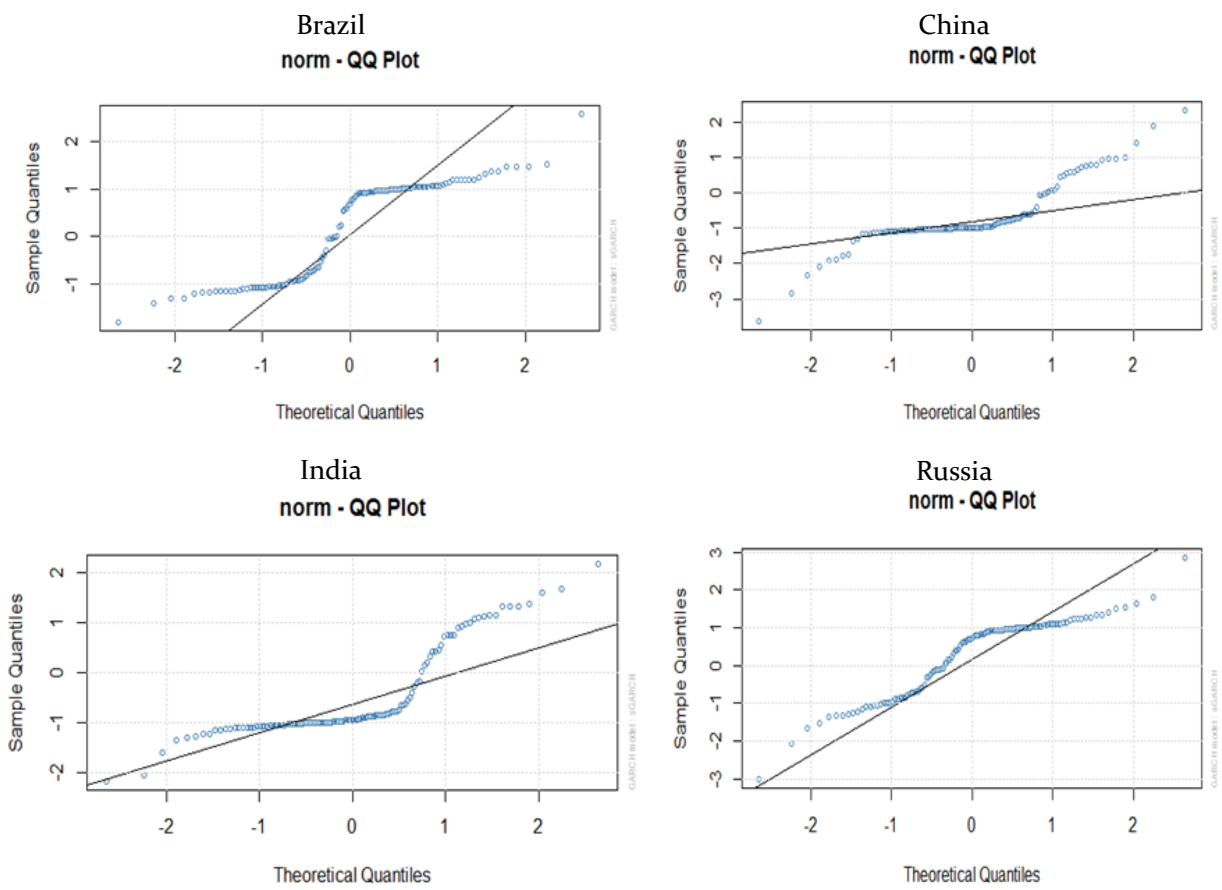

South Africa norm - QQ Plot

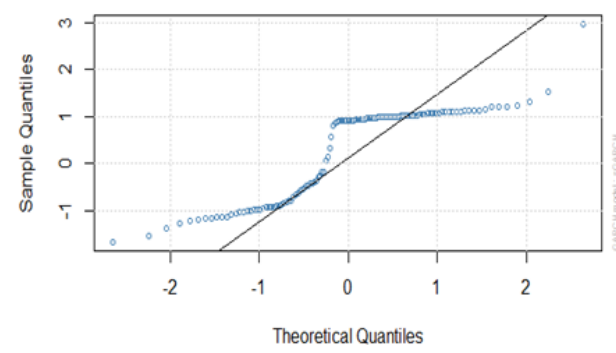

Figure 2: Q-Q plots for BRICS exchange rates

The above Figure 2 depicts that all the BRICS exchange rates points lie outside of the normal line. Therefore it is concluded that all the BRICS exchange rates Q-Q plots does not follow a normal distribution. The Table 4 below shows the summary table of DCC-GARCH (1.1) model parameter estimates for each of the BRICS exchange rates. 
Table 4: Summary table of DCC-GARCH (1.1) model parameter estimates for each of the BRICS exchange rates

\begin{tabular}{|c|c|c|c|c|c|}
\hline Exchange Rates & Parameter & Estimate & Std. Error & t-value & p-value \\
\hline \multirow{4}{*}{ Brazil } & $\mu$ & 0.709 & 0.025 & 28.637 & $0.000 * * *$ \\
\hline & $\Omega$ & 0.001 & 0.001 & 1.031 & 0.302 \\
\hline & $\alpha_{1}$ & 0.999 & 0.413 & 2.419 & $0.016^{*}$ \\
\hline & $\beta_{1}$ & 0.000 & 0.427 & 0.000 & 1.000 \\
\hline \multirow{4}{*}{ China } & $\mu$ & 1.922 & 0.026 & 73.831 & $0.000 * * *$ \\
\hline & $\Omega$ & 0.000 & 0.0001 & 0.006 & 0.995 \\
\hline & $\alpha_{1}$ & 0.852 & 0.327 & 2.604 & $0.009^{* *}$ \\
\hline & $\beta_{1}$ & 0.147 & 1.753 & 0.084 & 0.933 \\
\hline \multirow{4}{*}{ India } & $\mu$ & 4.162 & 0.022 & 186.973 & $0.000 * * *$ \\
\hline & $\Omega$ & 0.00004 & 0.00003 & 1.592 & 0.111 \\
\hline & $\alpha_{1}$ & 0.774 & 0.088 & 8.773 & $0.000 * * *$ \\
\hline & $\beta_{1}$ & 0.208 & 0.081 & 2.558 & 0.011 * \\
\hline \multirow{4}{*}{ Russia } & $\mu$ & 3.432 & 0.012 & 290.482 & $0.000^{* * *}$ \\
\hline & $\Omega$ & 0.0004 & 0.0002 & 2.124 & 0.034 * \\
\hline & $\alpha_{1}$ & 0.820 & 0.094 & 8.721 & $0.000^{* * *}$ \\
\hline & $\beta_{1}$ & 0.179 & 0.109 & 1.651 & $0.099^{\circ}$ \\
\hline \multirow{4}{*}{ South Africa } & $\mu$ & 2.120 & 0.014 & 150.892 & $0.000^{* * *}$ \\
\hline & $\Omega$ & 0.001 & 0.002 & 0.607 & 0.544 \\
\hline & $\alpha_{1}$ & 0.962 & 0.159 & 6.040 & $0.000 * * *$ \\
\hline & $\beta_{1}$ & 0.037 & 0.179 & 0.209 & 0.834 \\
\hline
\end{tabular}

Note: “***', ‘**', ‘*' and '.' indicates significant codes at $0.001,0.01,0.05$ and 0.1 respectively”.

The following models are deduced from the above Table 4, the DCC-GARCH (1.1) model equations for each BRICS exchange rates are written as follows

$$
\begin{aligned}
& x_{r}(\text { Brazil })=0.709( \pm 0.025)+\varepsilon_{t}, \\
& \sigma_{t}^{2}=0.001( \pm 0.001)+0.999( \pm 0.413) \sigma_{t-1}^{2}+0.000( \pm 0.427) \sigma_{t-1}^{2} \\
& x_{r}(\text { China })=-0.000( \pm 0.0001)+\varepsilon_{t}, \\
& \sigma_{t}^{2}=0.000( \pm 0.0001)+0.852( \pm 0.327) \sigma_{t-1}^{2}+0.147( \pm 1.753) \sigma_{t-1}^{2} \\
& x_{r}(\text { India })=4.162( \pm 0.022)+\varepsilon_{t} \\
& \sigma_{t}^{2}=0.00004( \pm 0.00003)+0.774( \pm 0.088) \sigma_{t-1}^{2}+0.208( \pm 0.081) \sigma_{t-1}^{2} \\
& x_{r}(\text { Russia })=3.423( \pm 0.012)+\varepsilon_{t}, \\
& \sigma_{t}^{2}=0.0004( \pm 0.0002)+0.820( \pm 0.094) \sigma_{t-1}^{2}+0.179( \pm 0.109) \sigma_{t-1}^{2} \\
& x_{r}(\text { SouthAfrica })=2.120( \pm 0.014)+\varepsilon_{t}, \\
& \sigma_{t}^{2}=0.001( \pm 0.002)+0.962( \pm 0.159) \sigma_{t-1}^{2}+0.037( \pm 0.179) \sigma_{t-1}^{2}
\end{aligned}
$$

$x_{r}$ represents the exchange rates for each of the BRICS countries whereas $\sigma_{t}^{2}$ illustrates the volatility part of the DCC-GARCH (1.1) model equation for each BRICS exchange rates. The sum of the estimates $\hat{\alpha}_{1}$ and $\hat{\beta}_{1}$ of all the BRICS exchange rates series are less than one meaning that the unconditional volatility for each of the BRICS exchange rates series is finite. The results further revealed that Brazil, China, Russia and South Africa has the highest volatility persistence value of $\hat{\alpha}_{1}+$ $\hat{\beta}_{1}=0.999$, and India has the least volatility persistence value of $\hat{\alpha}_{1}+\hat{\beta}_{1}=0.982$. The Figure 3 below shows the BRICS conditional volatility. 
Brazil

Conditional SD (vs |returns|)

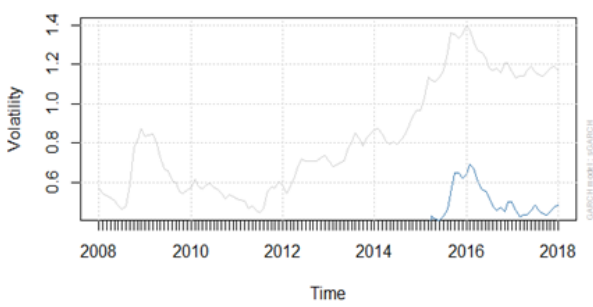

India

Conditional SD (vs Ireturns)

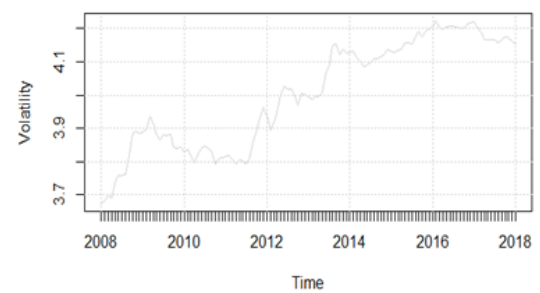

South Africa

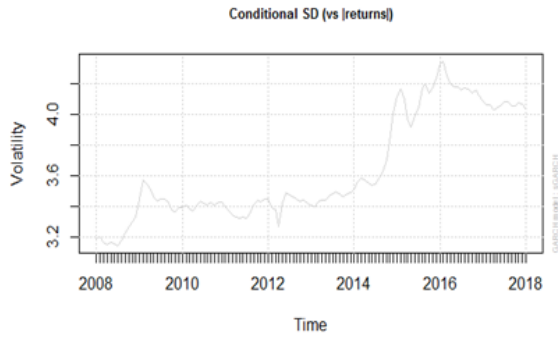

China

Conditional SD (vs Ireturns)

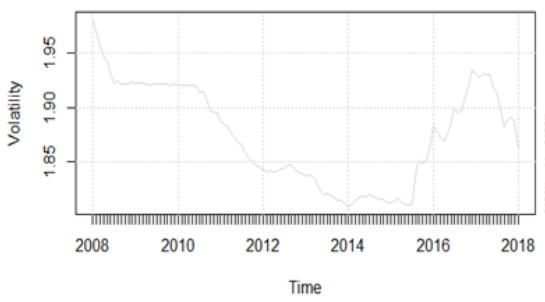

Russia

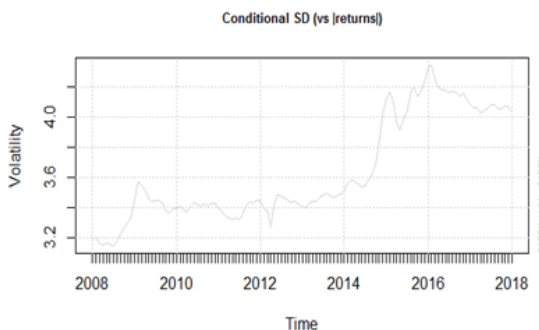

Figure 3: BRICS conditional volatility

The volatility scales in Figure 3 above shows that India has the highest volatility followed by Russia, South Africa, China and Brazil is least volatile. The next Figure 4 illustrates Time-varying conditional correlations from the DCC model.
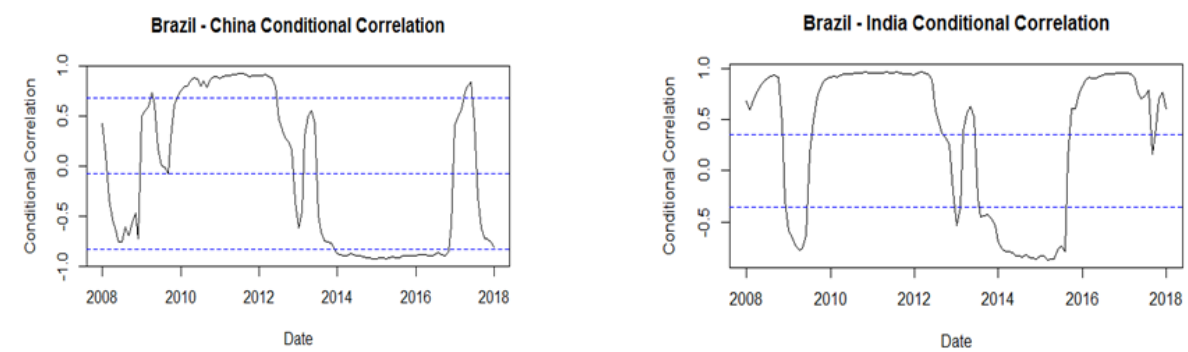

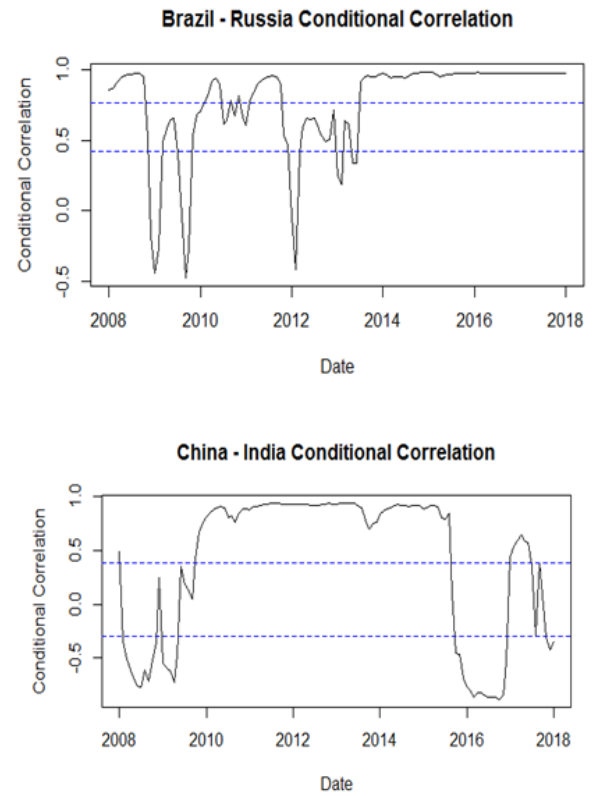

China - SouthAfrica Conditional Correlation

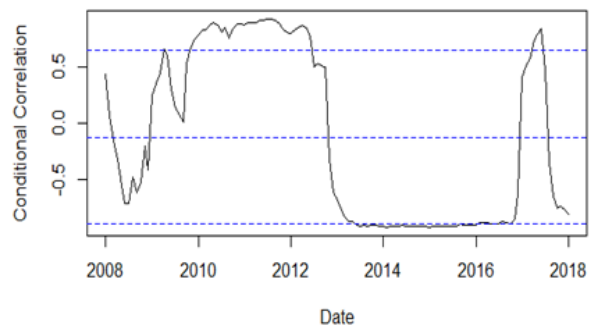

India - SouthAfrica Conditional Correlation

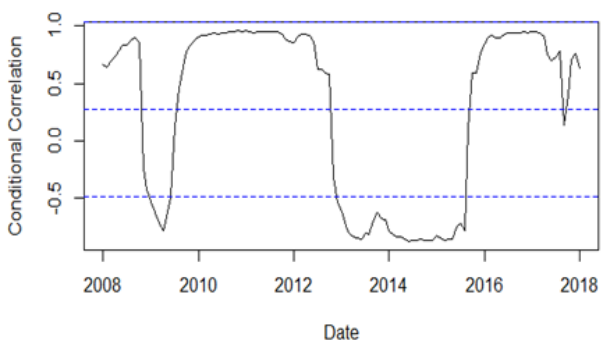

Brazil - SouthAfrica Conditional Correlation

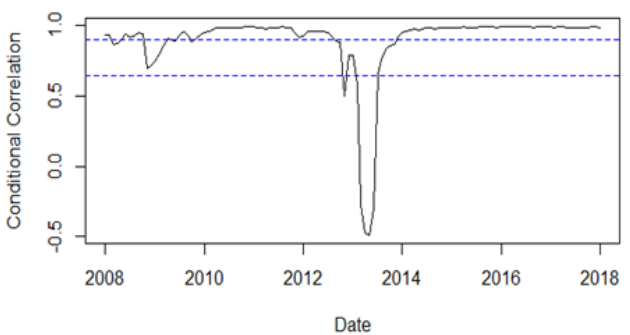

China - Russia Conditional Correlation

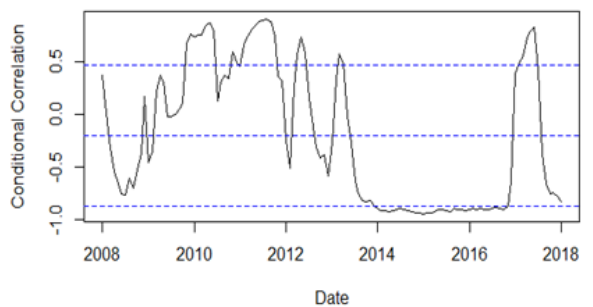

India - Russia Conditional Correlation

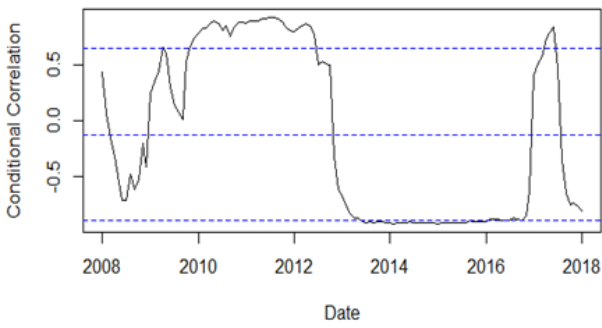

Russia - SouthAfrica Conditional Correlation

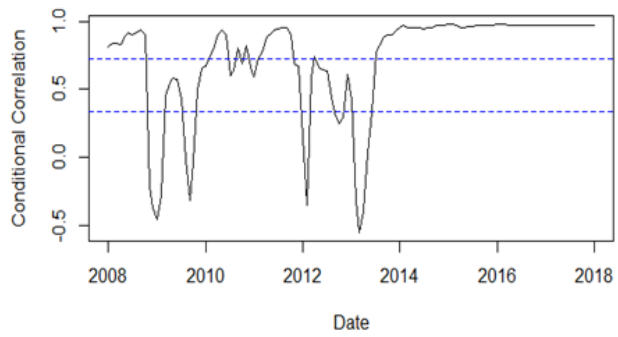

Figure 4: Time-varying conditional correlations from the DCC model

The above Figure 4 illustrates the time-varying conditional correlation between two countries at a time. DCC model was used in the construction of such conditional correlations. Brazil-China, Brazil- 
India, China-South Africa, and India-South Africa presented a similar pattern. The conditional correlation dynamic ranges between -1.0 and 1.o except for China-South Africa are within the ranges of between -0.5 and 1.0.

Brazil-Russia conditional correlation is on the main in the range between o.o and 1.o indicating that the majority of the data values are on the positive side of the correlation. Brazil-South Africa conditional correlation is also on the main positively correlated. The China-South Africa and IndiaRussia presents a similar pattern with the conditional correlation dynamic ranging between -0.5 and 1.o. China-Russia and Russia-South Africa also presents the similar pattern with the conditional correlation dynamic ranging between -0.5 and 1.o.

\subsubsection{Diagnostic tests}

Model adequacy testing is done using the following diagnostic tests: goodness of fit test; Ljung-Box (R), Ljung-Box (R2), and ARCH-LM. The diagnostic tests are presented in Table 5 below.

Table 5: Diagnostic test of the DCC-GARCH (1.1) model

\begin{tabular}{|c|c|c|c|}
\hline Exchange Rates & Diagnostic test & Statistic & p-value \\
\hline \multirow{4}{*}{ Brazil } & Goodness of fit test & 209.700 & $3.891 \mathrm{e}-34^{* * *}$ \\
\hline & Ljung-Box (R) & 102.100 & $0.000 * * *$ \\
\hline & Ljung-Box $\left(\mathrm{R}^{2}\right)$ & 4.593 & $0.032^{*}$ \\
\hline & ARCH-LM & 0.409 & 0.523 \\
\hline \multirow{4}{*}{ China } & Goodness of fit test & 361.800 & $3.685 \mathrm{e}-65^{* * *}$ \\
\hline & Ljung-Box (R) & 60.860 & $6.106 \mathrm{e}-15^{* * *}$ \\
\hline & Ljung-Box $\left(\mathrm{R}^{2}\right)$ & 9.869 & $0.002^{* *}$ \\
\hline & ARCH-LM & 2.510 & 0.113 \\
\hline \multirow{4}{*}{ India } & Goodness of fit test & 373.000 & $1.730 \mathrm{e}-67^{* * *}$ \\
\hline & Ljung-Box (R) & 87.170 & $0.000 * * *$ \\
\hline & Ljung-Box $\left(\mathrm{R}^{2}\right)$ & 0.290 & 0.590 \\
\hline & ARCH-LM & 0.057 & 0.812 \\
\hline \multirow{4}{*}{ Russia } & Goodness of fit test & 0.383 & 0.702 \\
\hline & Ljung-Box $(\mathrm{R})$ & 77.440 & $0.000 * * *$ \\
\hline & Ljung-Box $\left(\mathrm{R}^{2}\right)$ & 0.769 & 0.381 \\
\hline & ARCH-LM & 1.404 & 0.236 \\
\hline \multirow{4}{*}{ South Africa } & Goodness of fit test & 332.400 & $4.406 \mathrm{e}-59^{* * *}$ \\
\hline & Ljung-Box (R) & 97.210 & $0.000^{* * *}$ \\
\hline & Ljung-Box $\left(\mathrm{R}^{2}\right)$ & 0.281 & 0.596 \\
\hline & ARCH-LM & 1.273 & 0.259 \\
\hline
\end{tabular}

Note: “***), ‘**', ‘*’ and ‘' indicates significant codes at 0.001, 0.01, 0.05 and 0.1 respectively”.

The data in the above Table 5 shows that all the BRICS exchange rates have no ARCH errors, since all the p-values of the ARCH-LM test are greater than 0.05 level of significance. The Ljung-Box $\left(\mathrm{R}^{2}\right)$ revealed that the residuals of the squared BRICS exchange rates do not have serial correlation. All the BRICS exchange rates show that the fitted residuals are not normally distributed except for Russia which has a p-value more than 0.05. The Q-Q plots in Figure 2 for BRICS exchange rates are in support of the above assertion that the fitted residual are not normally distributed except for Russia.

\section{Conclusion}

The extension of the univariate GARCH model using a Multivariate approach was investigated and presented. The results showed that most of the variables were statistically significant. The estimates of the diagonal parameters shows that only Russia and South Africa were statistically significant 
which implied that the conditional variance of Russia and South Africa's exchange rates are affected by their own past conditional volatility and other BRICS exchange rates past conditional volatility. This is supported by the study by Bala and Takimoto (2017)

There was only one pair ( $G_{45}$ and $G_{54}$ ) of the off diagonal parameter which was found to be statistically significant thus illustrating a bidirectional volatility transmission between Russia and South Africa. There was a unidirectional volatility transmission found between Brazil and India; Russia and Brazil; Russia and China; South Africa and Brazil; South Africa and China; and South Africa and India. This results are supported by the study by Ijumba (2013).

The Multivariate GARCH model using a DCC approach was also presented and it provided for the dynamic relations amongst the BRICS exchange rates. All the BRICS exchange rates Q-Q plots did not follow a normal distribution. The results further revealed that Brazil, China, Russia and South Africa had the highest volatility persistence and India has the least volatility persistence. The timevarying conditional correlation between two countries at a time were presented using a DCC model. All the BRICS exchange rates show that the fitted residuals are not normally distributed except for Russia. The results are supported by the study by Bala and Takimoto (2017) and Ijumba (2013). The same study could be undertaken to determine the strength of different models in VAR enhanced BEKK-GARCH, VAR enhanced CCC-GARCH, and VAR enhanced DCC-GARCH models on the time varying integrated data. A similar study could also be conducted to investigate the performance of conditional heteroskedastic VEC enhanced GARCH models on the time varying integrated data may be conducted. This will assist in checking the results of the current study with other views relating to VEC enhanced GARCH model.

\section{References}

Baba, Y., Engle, R. F., Kraft, D. \& Kroner, K. (1990). Multivariate simultaneous generalized ARCH, unpublished manuscript, University of California, San Diego

Bala, D. A. \& Takimoto, T. (2017). Stock markets volatility spill-overs during financial crises: A DCC-Multivariate GARCH with skewed-t density approach. Borsa Istanbul Review, 17(1), 25-48.

Baybogan, B. (2013). Empirical investigation of multivariate GARCH Models. Journal of Statistical and Econometric Methods, 2, 75-93.

Bollerslev, T., Engle, R. F., \& Wooldridge, J. M. (1988). A capital asset pricing model with time-varying covariances. Journal of political Economy, 96(1), 116-131.

Bollerslev, T. (1986). Generalized autoregressive conditional heteroskedasticity. Journal of Econometrics, 31, 307327.

Bollerslev, T. (1990). Modeling the coherence in short-run nominal exchange rates: A Multivariate generalized ARCH model. The review of Economics and Statistics, 498-505.

Bonga-Bonga, L. \& Nleya, L. (2016). Assessing portfolio market risk in the BRICS economies: use of Multivariate GARCH models.

Breusch T. S. (1978). Testing for autocorrelation in dynamic linear models. Australian Economic Papers, 17, 334355 .

Bunnag, T. (2015). Hedging petroleum futures with Multivariate GARCH Models. International Journal of Energy Economics and Policy, 5(1), 105-120.

Chen, R. \& Zapata, H. O. (2015). Dynamics of price volatility in the China-US Hog industries. Annual Meeting, January 31-February 3, 2015, Atlanta, Georgia, 2015. Southern Agricultural Economics Association.

Efimova, O. \& Serletis, A. (2014). Energy markets volatility modeling using GARCH. Energy Economics, 43, 264-273 GARDEBROEK, C., HERNANDEZ, M. A. \& ROBLES, M. (2013). Market interdependence and volatility transmission among major crops.

Engle, R. (2002). Dynamic conditional correlation: A simple class of Multivariate generalized autoregressive conditional heteroskedasticity models. Journal of Business \& Economic Statistics, 20(3), 339-350.

Engle, R. F. \& Kroner, K. F. (1995). Multivariate simultaneous generalized ARCH. Econometric theory, 11(o1), 122150 .

Hartman, J. \& Sedlak, J. (2013). Forecasting conditional correlation for exchange rates using Multivariate GARCH models with historical value-at-risk application. 
Ijumba, C. (2013). Multivariate analysis of the BRICS financial markets. $1^{\text {st }}$ edition. Pietermaritzburg: School of Mathematics, Statistics and Computer Science. Print.

Kroner, K. F. \& Ng, V. K. (1998). Modeling Asymmetric Comovement of Asset Returns. Review of Financial Studies, 11, 122-150.

Kvasnakova, K. (2009). Modeling dependence structure of the stock and bond market. Comenius University, Bratislava. Google Scholar.

Ljung, G. M. \& Box, G. E. (1978). On a measure of lack of fit in time series models. Biometrika, 65(2), $297-303$.

Longin, F. \& Solnik, B. (1995). Is the correlation in international equity returns constant: 1960-1990?. Journal of international money and finance, 14(1), 3-26.

Longin, F. \& Solnik, B. (2001). Extreme correlation of international equity markets. The journal of finance, 56(2), $649-676$.

Mad'ar, M. M. (2014). Multivariate GARCH. Unpublished thesis. Univerzita Karlova v Praze

Minović, J. (2017). Application and diagnostic checking of univariate and Multivariate GARCH Models in Serbian financial market. Economic analysis, 41, 73-87.

Minović, J. \& Simeunović, I. (2009). Applying Multivariate GARCH models in finance. 633-641.

Nortey, E. N., Ngoh, D. D., Doku-Amponsah, K. \& Ofori-Boateng, K. (2015). Modeling inflation rates and exchange rates in Ghana: Application of Multivariate GARCH models.

Palm, F. C. (1996). 7 GARCH models of volatility, Handbook of statistics, 14, 209,240

Sheu, H. J. \& Cheng, C. L. (2011). A study of U.S. and China's volatility spill-over effects on Hong Kong and Taiwan. African Journal of Business Management, 5, 5232-5240.

Tastan, H. (2006). Estimating time-varying conditional correlations between stock and foreign exchange markets. Physica A: Statistical Mechanics and its Applications, 36o, 445-458.

Türkyilmaz, S. \& Balibey, M. (2014). The relationships among interest rate, exchange rate and stock price: A BEKKMultivariate GARCH approach. International Journal of Economics, Finance and Management Sciences, 1, 166.

Yi, Z., Heng, C. \& Wong, W. K. (2009). China's stock market integration with a leading power and a close neighbor. Journal of Risk and Financial Management, 2, 38-74. 